\title{
Grid fault ride-through of an LCC-VSC tandem converter, used as a grid interface for a multi-MW wind turbine.
}

\author{
M A Parker*, S J Finney ${ }^{\dagger}$ \\ *Department of Electrical and Electronic Engineering, University of Strathclyde \\ 204 George Street, Glasgow, G1 1XW, UK, max.parker@strath.ac.uk, ${ }^{\dagger}$ University of Strathclyde, UK, \\ stephen.finney@strath.ac.uk
}

Keywords: Wind Turbine, Tandem Converter, Grid Fault, Power Electronics

\begin{abstract}
A tandem converter, consisting of a line-commutated converter in parallel with a voltage source active filter, is proposed as a grid interface for a 10 and 20MW superconducting wind turbine generator. A commutation assistance scheme is introduced which allows the active filter to regulate the commutation of the LCC thyristors. This can allow ride through of grid faults by enabling the LCC thyristors to continue commutating with reduced grid voltage, which enables the use of tandem converters as a grid interface for renewable energy sources. The commutation assistance scheme is verified using simulation.
\end{abstract}

\section{Introduction}

Current-source converters have been proposed for wind energy applications [1], and one study has shown that costs could be considerably lower than voltage-source converters of the same rating [2]. However the load-commutated converters under consideration can have trouble coping with grid codes in terms of harmonics and grid fault ride-through. These problems can be solved with the addition of voltage-source active filters, making a tandem converter [3-5]. In a tandem converter, the current-source converter handles the main power flow with low cost and losses, while the active filter ensures a smooth current waveform. In this case, the active filter rating is about $25 \%$ that of the overall system rating.

A tandem converter, consisting of a load-commutated converter (LCC) in parallel with a voltage-source active filter based on a cascaded multilevel inverter, has been proposed as a grid interface for a large superconducting wind turbine generator [6]. Superconducting generators, using superconductors for the field windings, could allow the potentially higher reliability of direct-drive generators [7,8], but without the associated problem of high structural mass [9]. This is possible due to the high airgap flux density produced by the superconducting field windings [10,11]. Superconducting generators are under investigation by several companies including General Electric [12], Converteam (now part of GE) [13], ASMC and Siemens, as well as the EUfunded INNWIND project.
Superconducting generators have several features which present challenges to the design of the power electronic converter:

- A slotless design is usually employed for the rotor and stator, giving a synchronous reactance of around 0.1-0.2 per-unit. This can lead to high switching ripple as well as a high short circuit current.

- Harmonic distortion in the armature currents can lead to AC losses in the superconducting field coils, which must be removed by the cryogenic cooling system, requiring significantly higher powers than the losses themselves.

- To limit the leakage flux in the field windings, the generators have a low pole pitch, leading to a low rated $\mathrm{AC}$ frequency, as low as $2 \mathrm{~Hz}$.

In the INNWIND project, generator and converter designs were investigated for 10 - and $20 \mathrm{MW}$ offshore wind turbines. While the conventional 3-level NPC converter was considered adequate for the application, and is proposed by GE for their generator design [12], the tandem converter design shown in Figure 1 was found to have several advantages. As well as potential cost and efficiency benefits, the use of a cascaded multilevel VSC and multiple series thyristors allows for tolerance of switching device faults $[14,15]$, reducing the chances of a generator short circuit and improving reliability compared with the NPC converter.

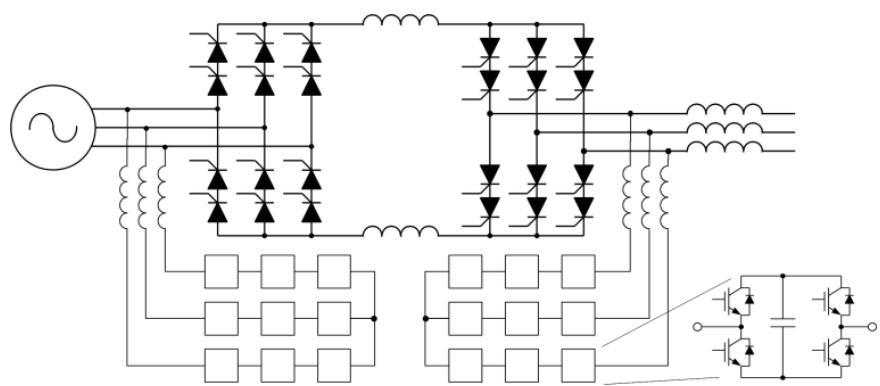

Figure 1: Tandem converter structure.

The tolerance of device faults could also be achieved using a modular multilevel converter (MMC) [16], but the low generator frequency means that the DC-link capacitance requirement is high. The filter in the tandem converter, operating only on the current harmonics and rated at a quarter 
of the overall power, has been found to have a significantly lower capacitance requirement [6].

Previously published research on the proposed generator and converter was concerned with the optimisation of the capacitance of the generator-side filter, as well as control of the generator side of the converter [6]. This paper aims to address the grid-side control of the converter and active filter, although overall control will also be discussed.

A significant issue with the use of LCCs for grid interfacing of generators is that grid fault ride-through is difficult, as the drop in grid voltage during the fault can cause the thyristor commutation to fail. Existing literature on tandem converters mainly concerns their use as a motor drive, so they do not consider this problem [3-5]. The solution proposed in this paper is to control the grid-side active filter to support the natural thyristor commutation. A further problem, relating to the superconducting generator is the extremely low generator frequency. During a significant grid voltage dip at higher generator speeds, the firing angle of the rectifier thyristors must be increased as the DC voltage has dropped, but the change cannot occur until after a zero-crossing of the generator current. The low generator frequency means that a significant overcurrent could arise in this time unless a very high DC-link inductance is used. To prevent any overcurrent, the generator-side active filter can be controlled to forcecommutate the rectifier thyristors, switching them instantly.

The structure of this paper is as follows: the parameters and design of the generator and converter will first be given. Controller design will be described, split into the design for normal operation and design for grid fault ride-through, with the latter containing details of the commutation assistance scheme. Simulation results will be presented, and finally conclusions given.

\section{Generator and Converter Parameters}

The main parameters for the generator and converter are given in Table 1. Both the generator- and grid-side filters use four series modules per phase, with the module capacitance optimised according to [6]. The grid filter switching frequency is set to give a current ripple of $5 \%$, with the 0.1 p.u. grid transformer leakage inductance acting as the filter inductance. The chosen generator filter switching frequency gives a generator current ripple of less than $1 \%$, but a lower frequency would lower the possible controller bandwidth as current sampling is synchronised to a multiple of the PWM frequency. A grid-side voltage of $3,500 \mathrm{~V}$ is used in order to allow the firing angle of the rectifier to be kept at zero during normal operation, while keeping the inverter firing angle below $170^{\circ}$ at rated power, in order to maintain controller stability.

\begin{tabular}{|l|l|}
\hline Power & $10 \mathrm{MW}$ \\
\hline Generator Rated Voltage & $3,300 \mathrm{~V}$ \\
\hline Generator Inductance & $21.6 \mathrm{mH}$ \\
\hline Generator Rated Frequency & $2.5 \mathrm{~Hz}$ \\
\hline
\end{tabular}

\begin{tabular}{|l|l|}
\hline Grid Voltage & $3,500 \mathrm{~V}$ \\
\hline Filter Series Modules & 4 \\
\hline DC-Link Inductance & $23 \mathrm{mH}$ \\
\hline Generator Filter Switch Frequency & $50 \mathrm{~Hz}$ \\
\hline Grid Filter Switch Frequency & $200 \mathrm{~Hz}$ \\
\hline Maximum Filter Module DC Voltage & $1,100 \mathrm{~V}$ \\
\hline Generator Filter Module DC Capacitance & $36.6 \mathrm{mF}$ \\
\hline Grid Filter Module DC Capacitance & $5.7 \mathrm{mF}$ \\
\hline
\end{tabular}

Table 1: Generator and converter parameters

\section{Controller Design}

Control of the converter can be split into three aspects. First is the general control of the active filter in order to achieve sinusoidal generator and grid currents, and this section will also include a general discussion of the filter operation. Secondly is the overall control of the converter, in order to achieve a given generator current demand, and regulate the DC-link current of the main converter and DC-link voltages of the filters. Finally grid fault ride-through control is covered, which is based around using the active filters for commutation assistance. The first two sections are covered briefly, as they have already been described in [6].

\subsection{Filter Operation and Control}

A single line diagram of the converter inverter side along with the current controller is shown in Figure 2. The inverter will produce a square wave current $i_{c}$, with magnitude and phase dependant on the main converter DC current $I_{D C}$ and firing angle $\alpha$. The grid current, $i_{g}$, must be sinusoidal, and is the sum of the inverter and filter currents $i_{c}$ and $i_{f}$. Typical current waveforms are shown in Figure 3.

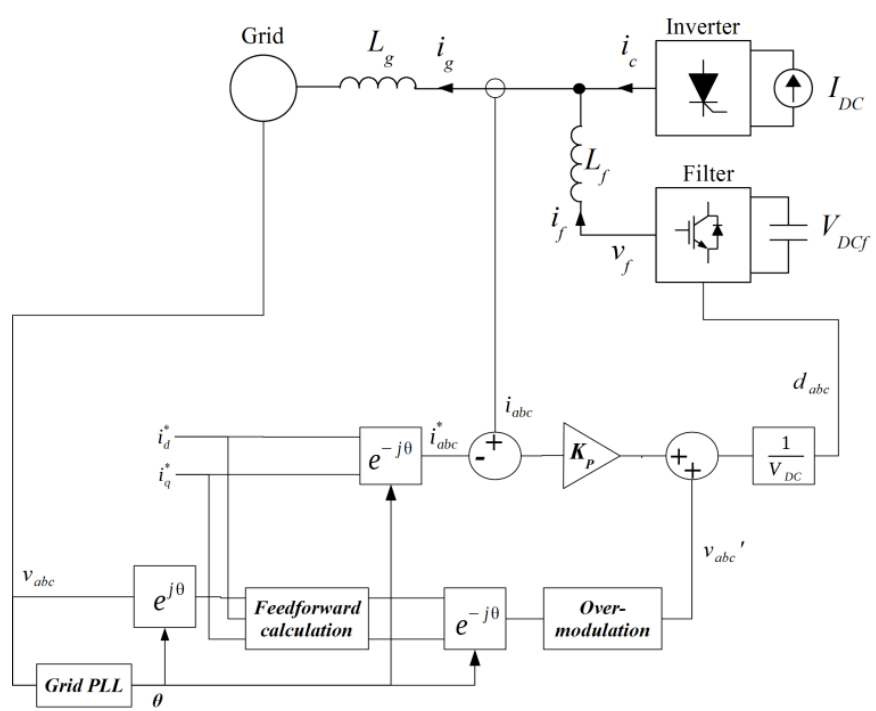

Figure 2: Single line diagram of converter inverter side and controller.

The complete converter is coupled to the grid via a coupling inductance $L_{g}$, and the voltage waveform produced by the multilevel active filter is smooth enough that the grid 
transformer leakage inductance provides sufficient filtering. The filter is coupled to the inverter via a coupling inductance $L_{f}$; the inverter thryistors commutate via the active filter, and this inductance is necessary to limit the rate of change of current during commutation. This will be discussed further in Section 3.3.

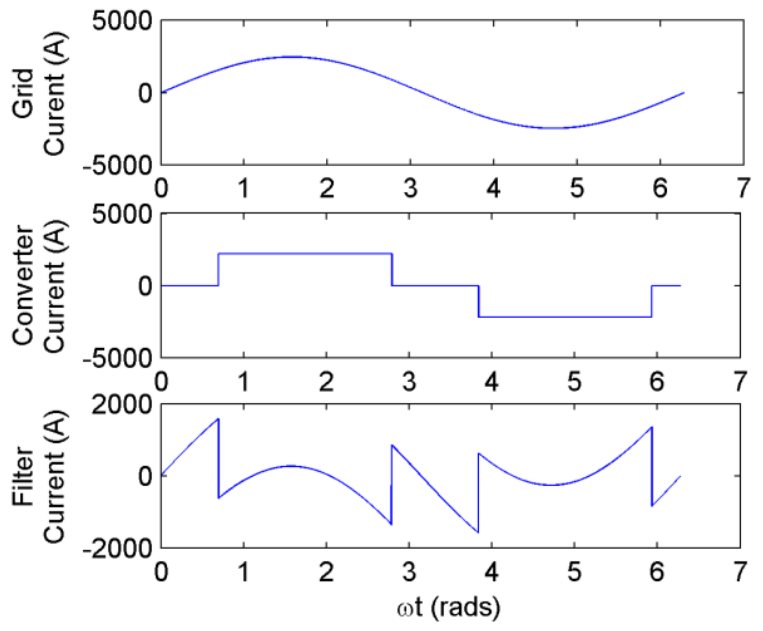

Figure 3: Typical inverter side currents.

Grid current is controlled using the active filter, based on dand q- axis current demands, $i_{d, q}^{*}$. Conventionally for VSCs, a vector current controller based in the rotating reference frame is used. This is less suitable in this case, due to the discontinuities which occur around thyristor commutation. Instead, a feedforward voltage is calculated in the rotating reference frame, then used to calculate voltages $v_{a b c}^{\prime}$. A proportional controller is used to regulate the current on a phase by phase basis, and mainly operates during thyristor commutation and transient changes in current demand. A similar system has successfully been used in an active rectifier scheme, in which similar discontinuities occur around the current zero crossings [15].

In the overall control scheme, described in Section 3.2, the firing angle of the inverter is used to regulate $I_{D C}$, depending on the generator current demand. For an ideal thyristor inverter, the RMS AC current is given by Equation (1), and the power factor given by Equation (2)[17]. These can be used to calculate a feedforward value for the d-axis current demand $I_{d}^{*}$, given by Equation (3). If this value is used, then the inverter and grid power flows will be balanced, and the DC voltages of the filter will be steady. As the converter is not ideal, the filter DC voltages must be actively regulated using a PI controller to set $I_{d}^{*}$, using the value from Equation (3) as a feedforward term to improve response speed. In addition, voltage balance between phase strings in the active filter must be regulated, as well as balance between modules in each string. These are covered in more detail in [m] for the rectifier side, and will not be covered here.

$$
I_{r m s}=\frac{\sqrt{2}}{\sqrt{3}} I_{D C}
$$

$$
\begin{gathered}
P F=\frac{3}{\pi} \cos \alpha \\
I_{d}^{*}=\frac{\sqrt{6}}{\pi} I_{D C} \cos \alpha
\end{gathered}
$$

\subsection{Overall Control}

In a similar manner to the grid filter, the generator filter is controlled to set the generator current and hence the generator torque. In this case, the generator current demand is set directly, and the generator filter DC-link voltage is regulated through the main converter DC-link current demand $i_{D C}^{*}$. The DC-link current itself is controlled through the inverter firing angle $\alpha$. In normal operation, the rectifier is operated with a firing angle of zero, with the same functionality as a passive rectifier. During grid voltage dips, $\alpha$ is held at $170^{\circ}$ and $i_{D C}$ regulated using the rectifier firing angle.

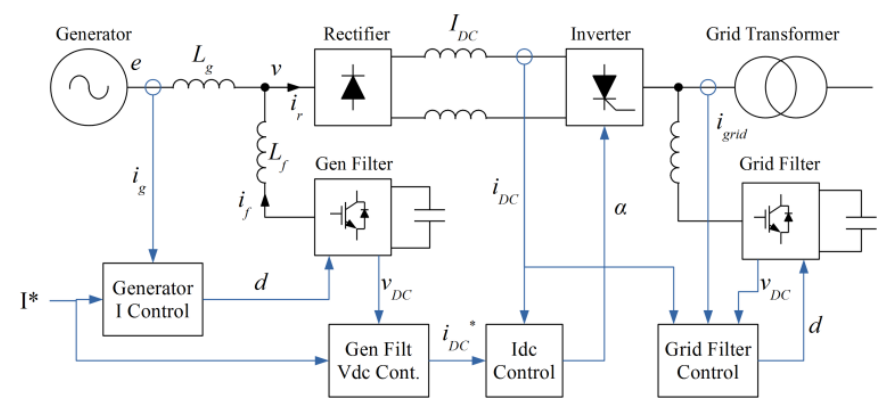

Figure 4: Overall controller structure.

\subsection{Grid Fault Ride-Through}

This paper is mainly concerned with the commutation assistance scheme, to allow inverter commutation during grid voltage dips and also to force commutate the rectifier, which are the basic requirements for grid fault ride-through of a tandem converter. A comprehensive operating strategy for operation during grid faults is incomplete at this stage, but some issues will be discussed in the conclusion.

Commutation of a grid connected thyristor-based inverter is shown in Figure 5, which represents a commutation between devices 1 and 3 . In this diagram the grid voltage is $v_{a b c}$, a current of $i_{D C}$ flows, which can be assumed to be constant, and the thyristors commutate through an inductance $L$. For commutation to occur when thyristor 3 is triggered, $v_{b}$ must be greater than $v_{a}$, with the current slope given by Equation (4).
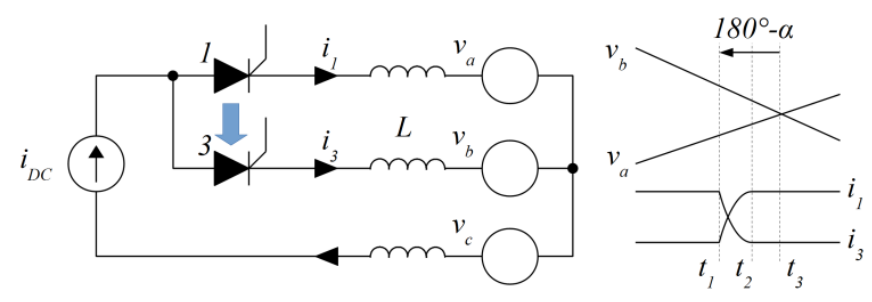

Figure 5: Inverter commutation. 


$$
\frac{d i}{d t}=\frac{1}{2 L}\left(v_{b}-v_{a}\right)
$$

At time $t_{1}$, representing a firing angle of $180^{\circ}-\alpha$, thyristor 3 is fired, with the commutation completing at time $t_{2}$, before $v_{b}$ and $v_{a}$ cross at time $t_{3}$. In order for commutation to be successful, $t_{3}-t_{2}>t_{q}$, where $t_{q}$ is the turn-off time of the thyristor and is around $1.5 \mathrm{~ms}$ for the devices under consideration.

In a conventional grid connected LCC, $L$ is generally large as it consists of the grid coupling inductance as well as the inductance of the grid itself. In addition, $d i / d t$ must be limited during normal operation, to prevent damage to the thyristors. Because of this, during a grid fault when much lower grid voltages are present, $d i / d t$ may be too low to allow the thyristors to commutate in time.

If an active filter is present, then the filter inductance $L_{f}$ will be much lower than the grid inductance $L_{g}$, and the thyristors will commutate through the filter. While the filter voltages will generally follow the grid voltages, they can be temporarily changed to assist commutation. If $L_{f} \ll L_{g}$, the impact on the grid current will be minimised. $L_{f}$ determines $d i / d t$ during thyristor commutation, which must be kept within the limits of the devices, and this is achieved by limiting the commutation voltage $v_{\text {com }}$ during the commutation interval.

The operation of the commutation assistance scheme is shown in Figure 6(a) for normal operation. Voltages are represented as continuous slopes, but in reality they will be multilevel PWM switched voltages. At time $t_{0}$, before the start of commutation, voltages $v_{a}$ and $v_{b}$ are ramped to an identical value, to allow the thyristors to switch at zero voltage. At time $t_{1}$ thyristor 3 is fired, and the voltage difference is raised to $v_{\text {com }}$, which is a multiple of the filter module DC-link voltages and therefore a constant value without PWM switching. After commutation the voltages are returned to their normal values. In this case, $v_{\text {com }}$ is lower than would be achieved without commutation assistance, maintaining a low $d i / d t$.

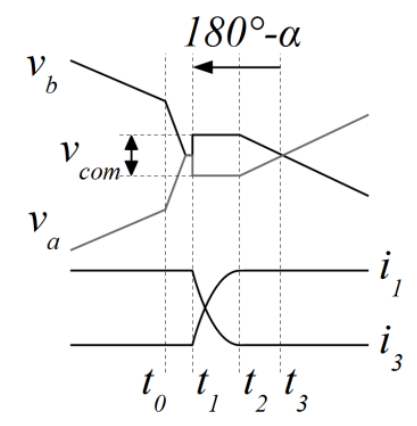

(a)

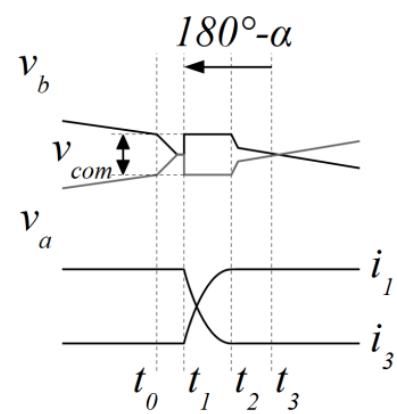

(b)
Figure 6: Commutation assistance with (a) Normal grid voltage, (b) Reduced grid voltage.
Operation with a reduced grid voltage is shown in Figure 6(b). Here $v_{\text {com }}$ is greater than would normally be achieved, allowing commutation within the time limit.

Forced commutation is also possible, when $v_{a}>v_{b}$, and this is shown in Figure 7. At $t_{0}$ the voltages are ramped together as before, and thyristor 3 fired at $t_{1}$ and the voltage difference increased to the commutation voltage. After commutation, the commutation voltage must still be held for time $t_{q}$ to prevent the commutation reversing, after which the voltages are returned to their normal values.

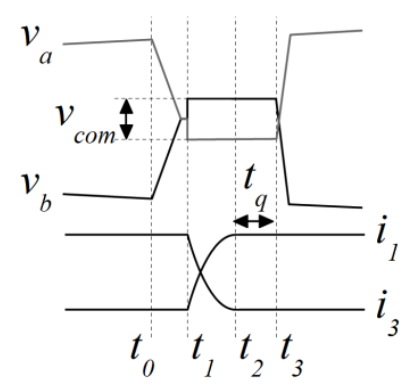

Figure 7: Forced commutation operation.

\section{Simulation Results}

Converter operation was simulated using Simulink and SimPowerSystems. Normal operation of the inverter is shown in Figure 8, in which the operation of the commutation assistance scheme can be seen in the filter voltage around the thyristor switching events.
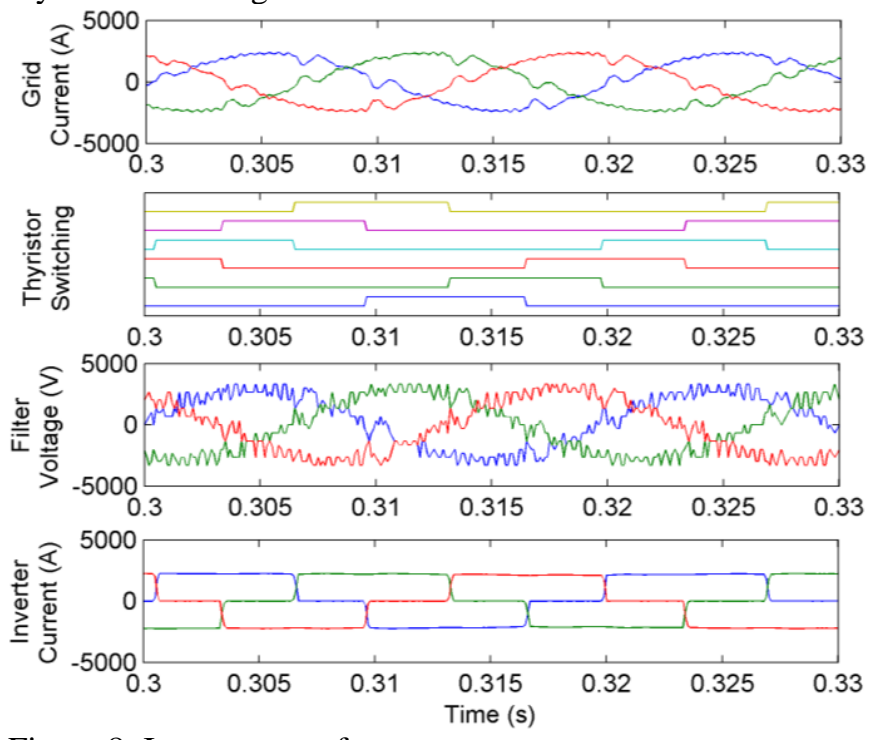

Figure 8: Inverter waveforms.

Some distortion can be seen in the grid current around the switching events even though the filter coupling inductance is a factor of 10 smaller than the grid coupling inductance, which is undesirable. This distortion could be reduced with a smaller filter inductance, allowing easier commutation, but 
this would increase the $d i / d t$ during commutation, towards the thyristor's limits. Alternatively a higher grid coupling inductance could be used, but this would increase cost and weight.

The commutation action is shown in more detail in Figure 9, which shows the two filter voltages brought together at the thyristor switching instance, then set to a limited difference to allow commutaiton to occur. At this stage, a gentle ramp in filter voltage has not been implemented, and some technical issues mean that the thyristor trigger pulse occurs at the same time as the voltages are brought together rather than slightly later.
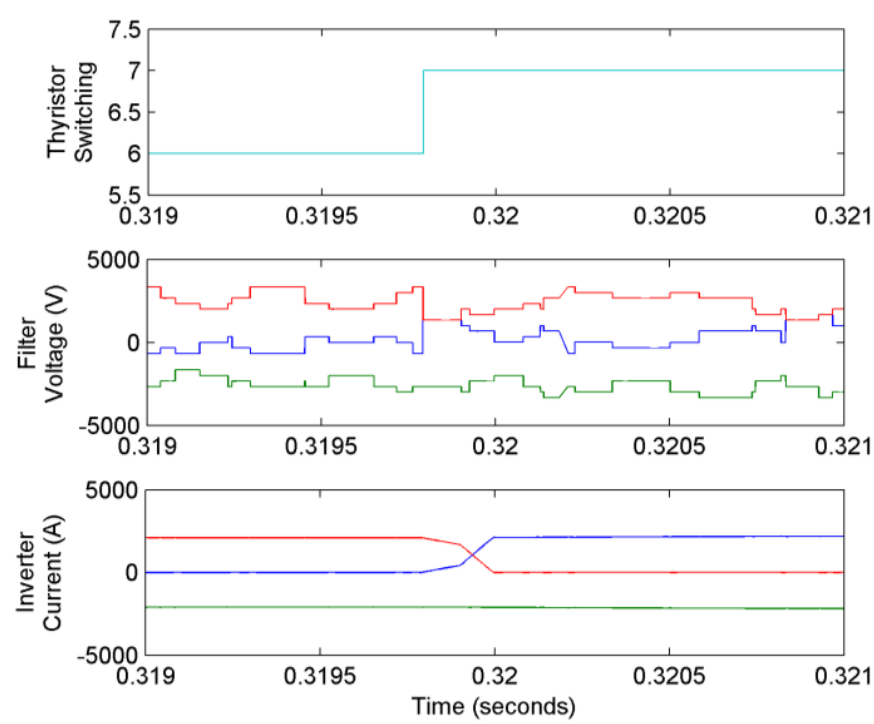

Figure 9: Detailed commutation action.

Response to a voltage dip is show in Figure 10. For simplicity of control, the grid voltage is reduced to almost zero at $0.5 \mathrm{~s}$, which would ordinarily allow the turbine to disconnect under most grid codes. This is done in order to avoid having to maintain control over the DC-link current: the rectifier is simply forced to a shoot-through state, and the current slowly coasts down, while the generator current is reduced to zero by the active filter. Force-commutation of the rectifier is demonstrated, as is commutation assistance of the inverter during the grid voltage dip, and the converter continues to supply rated current.

\section{Conclusions and Discussion}

A commutation assistance scheme for a LCC-VSC tandem converter has been demonstrated, in which the VSC active filter is used to assist commutation of the LCC main converter. During normal operation, the rate of change of current during commutation is limited, to protect the thyristors. During grid voltage dips, a commutation voltage is provided by the filter to support commutation with a reduced grid voltage. On the generator side, the rectifier can be forcecommutated, which is important if a generator with a low AC frequency is used, leading to a long time before the rectifier can be switched and a large increase in DC current.
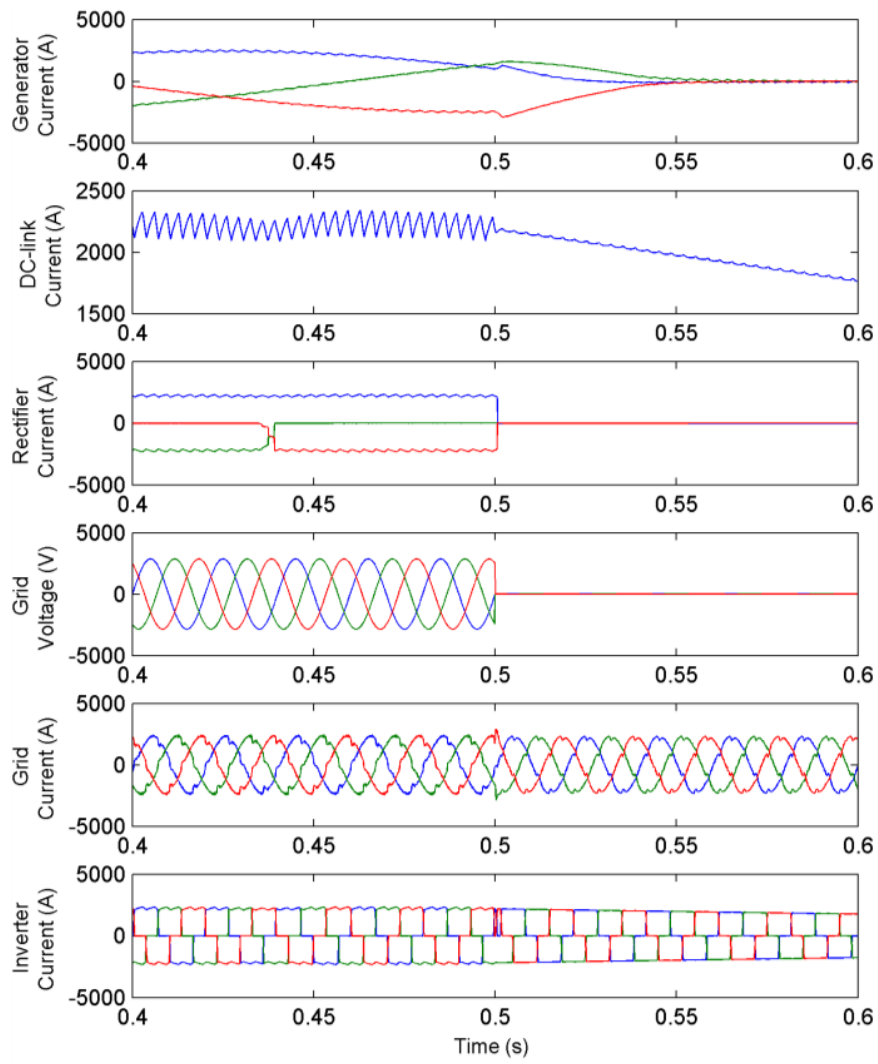

Figure 10: Response to a grid voltage dip.

The grid fault strategy is currently incomplete, as several issues remain:

- A dip down to almost zero volts was simulated at rated turbine power, allowing the rectifier to be disconnected. In reality, the voltage dips will be less severe, and the rectifier will continue operating at an increased firing angle, which may cause severe DC current ripple.

- A severe voltage dip will result in a rapid reduction in power export capability, and even reducing the generator current significantly will cause a large amount of power to be absorbed by the generatorside filter, raising the capacitor voltages. It may be necessary to add dump resistors to the generator terminals using an additional thyristor bridge, or to the generator filter.

- Simulation of fault ride-through was carried out at rated wind speed. At low wind speeds, the DC current will be significantly lower, but the converter will be expected to supply rated reactive current during a fault. As there will be a delay before the DC current can be increased, the reactive current may need to be supplied by the grid-side active filter, considerably increasing the rating and cost.

Additionally, the simulations were carried out using a relatively simple generic thyristor model, and commutation performance may differ in a real life situation. Nevertheless, 
this work shows that commutation assistance for the main LCC of a tandem converter is possible, and tandem converters could be a viable choice as a grid interface for wind energy and other distributed generating sources.

\section{Acknowledgements}

The research leading to these results has received funding from the European Community's Seventh Framework Programme FP7-ENERGY-2012-1-2STAGE under grant agreement No.308974 (INNWIND.EU), and the EPSRC's 'Underpinning Power Electronics 2012: Converters Theme' research programme (EP/K035304/1).

\section{References}

[1] Z. Chen, E. Spooner. "Grid interface options for variable-speed permanent-magnet generators," IEE Proc. Electr. Power Appl., 145 (4), (1998).

[2] R. Poore, T. Lettenmaier, "Alternative Design Study Report: WindPACT Advanced Wind Turbine Drive Train Designs Study," National Renewable Energy Laboratory (NREL), 2002.

[3] A. M. Trzynadlowski, F. Blaabjerg, J. K. Pedersen, and N. Patriciu. "The tandem inverter: Combining the advantages of voltage-source and current-source inverters," in Thirteenth Annual Applied Power Electronics Conference, APEC, (1998).

[4] G. Tadmor. "Control of a combined GTO/IGBT drive system for low torque ripple in a large permanent magnet synchronous motor," IEEE Trans. Control Syst. Technol., 12 (1), pp. 21-35, (2004).

[5] M. Imecs, A. M. Trzynadlowski, I. I. Incze, and C. Szabo. "Vector control schemes for tandem-converter fed induction motor drives," IEEE Trans. Power Electron., 20 (2), (2005).

[6] M. A. Parker, S. J. Finney. "Design of a Fault-Tolerant Tandem Converter for a Multi-MW Superconducting Offshore Wind Turbine Generator," IEEE Int. Conf. on Industrial Technology, ICIT, (2015).

[7] D. McMillan, G. W. Ault. "Techno-economic comparison of operational aspects for direct drive and gearbox-driven wind turbines," IEEE Trans. Energy Convers. 25 (1), pp. 191-198, (2010).

[8] P. J. Tavner, F. Spinato, G. J. W. van Bussel, E. Koutoulakos. "Reliability of different wind turbine concepts with relevance to offshore application," in International Wind Energy Conference, EWEC, (2008).

[9] A. S. McDonald, M. A. Mueller, H. Polinder. "Comparison of generator topologies for direct-drive wind turbines including structural mass," in Proc. Int. Conf. Electrical Machines, ICEM, (2006).

[10] A. Abrahamsen, N. Mijatovic, E. Seiler, T. Zirngibl, C. Traehold, P. B Norgard, N. F. Pedersen, N. H. Andersen, J. Ostergard. "Superconducting wind turbine generators," Superconductor Science and Technology, 23, (2010).

[11] H. Polinder, J. A. Fereira, B. B. Jensen, A. B. Arahamsen, K. Atallah, R. A. McMahon. "Trends in wind turbine generator systems," IEEE Trans. Emerg. Sel. Topics Power Electron., 1 (3), pp. 174-185, (2013).

[12] R. Fair, W. Stautner, M. Douglass, R. Rajput-Ghoshal, M. Moscinski, P. Riley, D. Wagner, J. Kim, S. Hou, F. Lopez, K. Haran, J. Bray, T. Laskaris, J. Rochford, R. Duckworth. "Superconductivity for large scale wind turbies," in Applied Superconductivity Conference, (2012).

[13] C. Lewis, J. Muller. "A direct-drive wind turbine HTS generator," in Power Engineering Society General Meeting, IEEE, (2007).

[14] B. Mirafzal. "Survey of fault-tolerance techniques for three-phase voltage source inverters," IEEE Trans. Ind. Electron., 61 (10), pp. 5192-5202, (2014).

[15] M. A. Parker, C. H. Ng, L. Ran. "Fault tolerant control for a modular generator-converter scheme for directdrive wind turbines," IEEE Trans. Ind. Electron. 58 (1), pp. 305-315, (2011).

[16] M. A. Perez, S. Bernet, J. Rodriguez, S. Kouro, R. Lizana. "Circuit topologies, modelling, control schemes and applications of modular multilevel converters," IEEE Trans. Power Electron., 30 (1), pp. 4-17, (2015).

[17] N. Mohan, T. Undeland, W. Robbins. "Power Electronics: Converters, Applications and Design," John Wiley \& Sons Inc., pp.138-143, 2003. 